\title{
Self-Management Behaviors of Patients with Hypertension in Daily Life
}

\author{
Ryoko Igarashi \\ Department of Medical Education, Tokyo Medical University, Tokyo, Japan \\ Email: igaryo@tokyo-med.ac.jp
}

How to cite this paper: Igarashi, R. (2019) Self-Management Behaviors of Patients with Hypertension in Daily Life. Open Journal of Nursing, 9, 561-585. https://doi.org/10.4236/ojn.2019.96047

Received: April 15, 2019

Accepted: June 25, 2019

Published: June 28, 2019

Copyright $\odot 2019$ by author(s) and Scientific Research Publishing Inc. This work is licensed under the Creative Commons Attribution International License (CC BY 4.0).

http://creativecommons.org/licenses/by/4.0/

\begin{abstract}
Background: In a rapidly aging Japanese society, the number of patients with hypertension has seen a steady increase. The basic treatments for hypertension are maintaining blood pressure through medication and preventing complications. It is important for patients with hypertension to perform self-management. This improves their lifestyle while controlling their blood pressure to prevent complications and maintain good health. Purpose: This study aimed to examine the actual self-management behavior ability of patients with hypertension and to clarify the factors involved in their self-management behavior. Methods: A total of 150 patients with hypertension were included in this study. The following data were obtained from the patients as background information: sex, age, years with disease, whether they are receiving antihypertensive agents, type of antihypertensive agent, blood test data, heart thoracic ratio, left ventricular ejection fraction, pulse wave, pulse wave velocity, and height. The levels of self-management skills of the patients were also assessed using the "Instrument to Measure the Self-care of patients with Hypertension" developed by Tsuboi et al. Results: The associations among self-management behaviors in daily life, such as diet, exercise, stress, medication, alcohol intake, and smoking, were analyzed in patients with hypertension. The subjects were classified into the following three groups: aged 65 years or below (Group A), early stage elderly individuals (Group B), and late-stage elderly individuals aged 75 years or over (Group C). The results showed that the subjects in Group C had higher self-management scores for diet, exercise, stress, medication, and drinking than the subjects in the other two groups. The scores of smoking and self-management of the subjects in Group A were high but their other self-management scores were low. All the subjects were taking between 1 to 3 types of oral antihypertensive drugs. The rate of achievement of the target blood pressure was $50 \%$ or more in all the three groups. However, the pulse wave velocity was high in all the three groups. Conclusion: The results indicate that the risk of developing
\end{abstract}


disorders of the brain and cardiovascular system is high in all the three groups, owing to the high degree of arteriosclerosis. Therefore, increasing the number of nursing interventions is expected to reduce blood pressure, maintain and promote self-management behavior in daily life, and prevent the onset of complications. The results suggest that nursing interventions involving lifestyle guidance for improving the self-management skills of patients are urgently needed by patients under 65 years of age.

\section{Keywords}

Self-Management, Patients with Hypertension, Management Behaviors

\section{Introduction}

The Westernization of lifestyles in Japan, including changes in dietary patterns, diversification of lifestyles, and a rapidly aging society, has led to changes in the structure of diseases. The number of patients with cardiovascular diseases, especially those with hypertension, has been increasing steadily [1]. In Japan, 43 million individuals are estimated to have hypertension. High blood pressure is associated with increased risk of developing cardiovascular diseases such as myocardial infarction and heart disease, and it is known to increase mortality rate. From young adults to elderly individuals, individuals with high blood pressure have been found to exhibit a higher incidence of cardiovascular diseases and related mortality [2]. Incidence of hypertension increases with age. In Japan, 33.92 million individuals were aged 65 years and over, accounting for $26.7 \%$ of the total population. Further, $63.2 \%$ of those aged between 65 and 74 years, and $74.2 \%$ of those aged 75 years and over are affected with hypertension [3]. Therefore, the number of elderly individuals with hypertension is expected to increase further in the future.

Ueshima et al. reported that the level of hypertension was positively correlated with the prevalence of cardiovascular disease [4]. Further, the prevalence of myocardial infarction was 3 to 6 times higher in males and 4 to 12 times higher in females with hypertension. Previous studies on the association between blood pressure and the risk of developing cardiovascular diseases reported that systolic blood pressure can predict prognosis [5] [6]. Additionally, Health Japan 21 reported that the risk of incidence of coronary artery disease and mortality increases about $15 \%$ with the elevation of systolic blood pressure by $10 \mathrm{mmHg}$. Since the higher systolic blood pressure increases the risk of complications and mortality, it is critical for patients with hypertension to maintain optimal blood pressure and to monitor their blood pressure regularly at home [7].

The basic treatments for hypertension are maintaining blood pressure through medication and preventing complications. Additionally, appropriate exercise to prevent obesity, and improvements in lifestyle, such as changes in the diet, enhance treatment effects by reducing complications or preventing the 
condition from becoming more severe. In this context, the World Health Organization (WHO) and International Society of Hypertension suggest the importance of lifestyle modification among patients with hypertension. It is important for such patients to perform self-management which improves lifestyle while controlling the blood pressure to prevent complications and maintain health. Hypertension is considered a chronic disease, thus, self-management should be performed regularly in the patient's daily life.

A previous study suggested that exercise therapy and limiting sodium intake are effective lifestyle modifications among patients with hypertension, and it acknowledged the need for self-management on a daily basis [8]. On the other hand, about half of the patients with hypertension are reported to perform inadequate self-management [9]. Therefore, there is an urgent need to consider strategies to improve the lifestyle of patients with hypertension and to maintain appropriate self-management in their daily life. It is also important to obtain basic information on the nursing care which ensures that patients with hypertension can improve and maintain their self-management behavior. Thus, this study aims to grasp the actual self-management behavior ability of patients with hypertension and to clarify the factors involved in their self-management behavior.

\section{Methods}

1) Study period: April 1 to September 30, 2015.

2) Study site: The outpatient clinic of the Department of Cardiology at Tokyo Medical University Hospital.

3) Selection criteria of the participants were as follows: outpatients were diagnosed with hypertension, who regularly booked their next appointment and visited the hospital for follow-up examinations. Subjects were defined as patients with hypertension who regularly visited the outpatient cardiology clinic.

4) Study context.

a) Study design: Survey

b) Study context

i) Background of participants.

Sex, age, disease duration, presence or absence of taking antihypertensive medications, type of antihypertensive medications taken, blood test results, cardiothoracic ratio, ejection fraction, ankle-brachial pressure index (ABI), pulse wave velocity (PWV), height, weight, body mass index (BMI), and blood pressure at medical examination.

ii) Survey on self-management behaviors.

A survey was conducted using the "Instrument to Measure the Self-care of patients with Hypertension" developed by Tsubota et al. Each item in this tool is scored on a four-point scale (yes, somewhat yes, somewhat no, and no), with 4 to 1 points awarded to the response options, respectively. Higher scores indicate that the participants perform appropriate self-management behaviors. 
5) Analysis method.

The score on the self-management behavior scale was the dependent variable, while the participants' basic attributes and clinical findings were the independent variables. Data were analyzed using the one-way analysis of variance, with the Bonferroni test for post-hoc multiple comparisons. Descriptive analysis was used to examine the participants' basic attributes. All analyses were conducted using IBM SPSS Statistics Ver.24.

\section{Ethical Considerations}

This study was approved by the Ethics Review Committee of the School of Nursing at Tokyo Medical University and Tokyo Medical University Hospital. The researcher orally explained the research objectives and participation details using instructions sheets to each participant. They were informed that participation in the study was voluntary and that they could withdraw consent at any time, even after agreeing to participate. They would receive no disadvantage as a result of leaving the study. It was also explained that personal information would be protected, that the research data would not be used for anything other than for the present study, and that all the data collected would be shredded after the completion of the study. Subsequently, those who agreed to participate in the study signed the consent form and completed the questionnaire. The survey was anonymous and participants did not need to fill in the questions that they did not want to answer. The patients were asked to place the completed questionnaire in a collection box after completing their medical examination at the outpatient clinic.

\section{Results}

1) Basic attributes of participants

Data were obtained from 150 participants (93 males and 57 females). Their mean age was $70 \pm 10.6$ years (ranging from 46 - 92 years). In the "Elderly people medical care system" in Japan, from the age of 65 to 74 is defined as the "early-stage elderly individuals" and the age 75 or older is defined as the "late-stage elderly individuals". The subjects were classified into group based on the definition. Participants were categorized into the following three groups by age: aged 65 years or below (Group A), early-stage elderly individuals (Group B), and late-stage elderly individuals aged 75 years or over (Group C) (Table 1). The duration of hypertension was two times longer in Group $\mathrm{C}$ as compared to that in Group A, with a statistically significant difference between the two groups ( $\mathrm{p}<$ 0.01 ). The average BMI in Group A was $26.2 \pm 4.7 \mathrm{~kg} / \mathrm{m}^{2}$, being classified in Obesity Class I and II. Further, those in Group B were distributed among normal weight or Obesity Class I, and those in Group C were classified as normal weight. There were significant differences among the three groups $(\mathrm{p}<0.01)$.

The average cardiothoracic ratios were $49 \% \pm 5.4 \%, 50.5 \% \pm 4.9 \%$, and $52 \% \pm$ $6.5 \%$ in Group A, B, and C, respectively, indicating an increasing trend in 
Table 1. Background factors among three groups of hypertension patients.

\begin{tabular}{|c|c|c|c|c|}
\hline Variable & $\begin{array}{c}\text { aged } 65 \text { years } \\
\text { or below } \\
\text { (Group A) } \\
(\mathrm{N}=45)\end{array}$ & $\begin{array}{l}\text { early-stage elderly } \\
\text { individuals } \\
\text { (Group B) } \\
(\mathrm{N}=52)\end{array}$ & $\begin{array}{c}\text { late-stage elderly } \\
\text { individuals aged } \\
75 \text { years or over } \\
\text { (Group C) } \\
(\mathrm{N}=53)\end{array}$ & \\
\hline Number of cases & 45 & 52 & 53 & \\
\hline Age & $57.2 \pm 5.2$ & $69.2 \pm 2.9$ & $81.6 \pm 4.3$ & \\
\hline Gender (Female \%) & $21.10 \%$ & $28.10 \%$ & $50.90 \%$ & \\
\hline Disease duration (year) & $5.8 \pm 4.8^{* *}$ & $8.4 \pm 5.1$ & $10.5 \pm 6.3^{\star *}$ & $\mathrm{AC}^{* *}$ \\
\hline $\begin{array}{l}\text { Body mass index } \\
\left(\mathrm{kg} / \mathrm{m}^{2} \leq\right) \mathrm{BMI}\end{array}$ & $26.2 \pm 4.7$ & $24.4 \pm 3.2$ & $23.4 \pm 3.9^{* *}$ & $\mathrm{C}^{* *}$ \\
\hline $\begin{array}{l}\text { blood pressure: SBP } \\
\quad(\mathrm{mmHg})\end{array}$ & $137 \pm 17$ & $136 \pm 16$ & $143 \pm 19$ & \\
\hline $\begin{array}{l}\text { blood pressure: DBP } \\
(\mathrm{mmHg})\end{array}$ & $80 \pm 11$ & $73 \pm 13$ & $70 \pm 12^{* *}$ & $\mathrm{C}^{* *}$ \\
\hline $\begin{array}{l}\text { Number of } \\
\text { antihypertensive } \\
\text { agents }\end{array}$ & $1.9 \pm 0.9$ & $2.2 \pm 1.2$ & $2 \pm 1.0$ & \\
\hline T-Cho (mg/dl) & $189.5 \pm 37.3$ & $184.2 \pm 33.7$ & $182.1 \pm 40$ & \\
\hline $\mathrm{TG}(\mathrm{mg} / \mathrm{dl})$ & $167.9 \pm 89$ & $157.1 \pm 83$ & $135 \pm 69$ & \\
\hline HDL-C (mg/dl) & $49 \pm 11.6$ & $48.9 \pm 15$ & $52.4 \pm 13.7$ & \\
\hline LDL-C (mg/dl) & $98.1 \pm 25$ & $94 \pm 25.4$ & $97.2 \pm 29.9$ & \\
\hline BUN (mg/dl) & $14.5 \pm 3.5$ & $16.7 \pm 5.0$ & $16.7 \pm 4.6$ & \\
\hline CRE (mg/dl) & $3.2 \pm 1.0$ & $0.84 \pm 0.2$ & $0.83 \pm 0.26$ & \\
\hline $\mathrm{UA}(\mathrm{mg} / \mathrm{dl})$ & $5.8 \pm 1.4$ & $5.6 \pm 1.4$ & $5.4 \pm 1.0$ & \\
\hline Glucose (mg/dl) & $117.7 \pm 36$ & $126.8 \pm 43$ & $113.8 \pm 26.2$ & \\
\hline HbAlc (\%) & $6.26 \pm 1.0$ & $6.15 \pm 0.82$ & $6.2 \pm 0.76$ & \\
\hline $\begin{array}{c}\text { Cardiothoracic ratio: } \\
\text { CTR }(\%)\end{array}$ & $49 \pm 5.4$ & $50.5 \pm 4.9$ & $52 \pm 6.5$ & \\
\hline $\begin{array}{l}\text { Left ventricular } \\
\text { ejection fraction: } \\
\text { EF (\%) }\end{array}$ & $62 \pm 13$ & $66 \pm 4.7$ & $65 \pm 4.1$ & \\
\hline $\begin{array}{l}\text { Ankle Brachial Index } \\
\text { (Rt): ABI (Rt) }\end{array}$ & $1.2 \pm 0 . .1$ & $1.1 \pm 0.8$ & $1.1 \pm 0.13$ & \\
\hline $\begin{array}{l}\text { Ankle Brachial Index } \\
\text { (Lt): ABI (Lt) }\end{array}$ & $1.19 \pm 0.09$ & $1.18 \pm 0.07$ & $1.12 \pm 0.1$ & \\
\hline $\begin{array}{l}\text { Pulse Wave Velocity } \\
\text { (Rt): PWV (Rt) }\end{array}$ & $1554.3 \pm 240$ & $1776 \pm 500$ & $2012 \pm 325$ & \\
\hline $\begin{array}{l}\text { Pulse Wave Velocity } \\
\text { (Lt): PWV (Lt) }\end{array}$ & $1550 \pm 256.5$ & $1849.2 \pm 573.4$ & $2037.5 \pm 327.7$ & \\
\hline
\end{tabular}

(Mean \pm SD). ${ }^{*} \mathrm{p}<0.05,{ }^{* *} \mathrm{p}<0.01$.

cardiac hypertrophy with age. On the other hand, ejection fraction was within the normal range in all three groups. There was no significant difference in other variables. The percentages of medical history of ischemic heart disease were 
$22.6 \%, 23.3 \%$, and $30.7 \%$ in Group A, B, and C, respectively. The percentages of medical history of cerebrovascular disease were $7.3 \%, 4.7 \%$, and $8 \%$ in Group A, $\mathrm{B}$, and $\mathrm{C}$, respectively (Table 1 ).

2) Self-management in daily life

The participants were classified into the following three groups based on age: individuals aged 65 years or below as Group A, early-stage elderly individuals as Group B, and late-stage elderly individuals as Group C. Then, these three groups were compared in terms of their self-management scores for diet, exercise, stress, medications, drinking habits, and smoking.

a) Diet management

As compared to participants in the other two groups, those in Group C exhibited higher self-management scores on the following 5 items: Item 1 (I refrain from foods high in sodium such as pickles, tsukudani [fish or seaweed boiled with soy], ham, himono [dried fish], and salted fish), Item 3 (I try to eat lightly flavored foods), Item 4 (I try not to gain weight), Item 5 (I refrain from meat and greasy foods), Item 6 (I refrain from sweet snacks and juices), and Item 7 (I eat foods with reduced sodium). As compared to participants in the other two groups, those in Group B exhibited higher self-management scores on Item 2 (I eat mainly vegetables and fish) and Item 8 (I avoid foods that contain cholesterol, such as eggs, fish eggs, fish eaten with internal organs, liver, and fatty part of meat). Participants in Group A exhibited lower self-management scores on all 8 items. There was a significant difference between the three groups in terms of scores on Item 2 (I eat mainly vegetables and fish) and Item 7 (I eat foods with reduced sodium) $(\mathrm{p}<0.05)$. The total score on the self-management of diet was significantly higher in participants in Group $\mathrm{C}$ as compared to those in the other two groups $(\mathrm{p}<0.05)$ (Table 2).

b) Exercise management

As compared to participants in the other two groups, those in Group C exhibited higher self-management scores on the following 5 items: Item 1 (I engage in moderate whole body exercise such as swinging arms and moving legs widely while taking a walk, walking quickly, exercise in the pool, swimming, cycling, calisthenics to the radio, and rhythmic exercise), Item 4 (I exercise indoors when the weather is bad), Item 6 (I drink water during and after exercise), Item 7 (I try to exercise regularly), and Item 8 (I try to get information about exercise treatment). Further, as compared to participants in the other two groups, those in Group B exhibited higher self-management scores on Item 2 (I measure my pulse during exercise and see if the exercise is putting a heavy burden on the body), Item 3 (I feel refreshed after exercise), and Item 5 (I try not to rely too much on vehicles like cars and walk instead). Participants in Group A exhibited lower scores on all 8 items. The total score on the self-management of exercise was the highest in Group C among the three groups (Table 3).

c) Stress

Participants in Group C exhibited the highest self-management scores on all 8 items as compared to those in the other two groups. In contrast, those in Group 
Table 2. Self management score in diet management.

\begin{tabular}{|c|c|c|c|c|}
\hline Item Description & $\begin{array}{c}\text { aged } 65 \text { years } \\
\text { or below } \\
(\text { Group A) } \\
(\mathrm{N}=45)\end{array}$ & $\begin{array}{l}\text { early-stage elderly } \\
\text { individuals } \\
(\text { Group B) }(\mathrm{N}=52)\end{array}$ & $\begin{array}{c}\text { late-stage elderly } \\
\text { individuals aged } 75 \\
\text { years or over } \\
\text { (Group C) }(\mathrm{N}=53)\end{array}$ & \\
\hline $\begin{array}{l}\text { 1) I refrain from foods high in } \\
\text { sodium such as pickles, } \\
\text { tsukudani [fish or seaweed } \\
\text { boiled with soy], ham, himono } \\
\text { [dried fish], and salted fish. }\end{array}$ & $2.62 \pm 0.93$ & $2.71 \pm 0.91$ & $3.13 \pm 0.81$ & \\
\hline $\begin{array}{l}\text { 2) I eat mainly vegetables } \\
\text { and fish) eat mainly vegetables } \\
\text { and fish. }\end{array}$ & $2.64 \pm 0.83$ & $3.22 \pm 0.75$ & $3.10 \pm 0.90$ & * \\
\hline $\begin{array}{l}\text { 3) I try to eat lightly flavored } \\
\text { foods. }\end{array}$ & $2.82 \pm 0.86$ & $2.85 \pm 0.91$ & $3.19 \pm 0.90$ & \\
\hline 4) I try not to gain weight. & $2.91 \pm 0.88$ & $3.02 \pm 0.96$ & $3.27 \pm 0.88$ & \\
\hline $\begin{array}{l}\text { 5) I refrain from meat and } \\
\text { greasy foods. }\end{array}$ & $2.76 \pm 0.85$ & $2.88 \pm 0.87$ & $3.19 \pm 0.83$ & \\
\hline $\begin{array}{l}\text { 6) I refrain from sweet snacks } \\
\text { and juices. }\end{array}$ & $2.98 \pm 0.78$ & $3.02 \pm 0.78$ & $3.02 \pm 0.97$ & \\
\hline $\begin{array}{l}\text { 7) I eat foods with reduced } \\
\text { sodium. }\end{array}$ & $2.73 \pm 0.89$ & $2.63 \pm 0.91$ & $3.14 \pm 0.92$ & * \\
\hline $\begin{array}{l}\text { 8) I avoid foods that contain } \\
\text { cholesterol, such as eggs, fish } \\
\text { eggs, fish eaten with internal } \\
\text { organs, liver, and fatty part of } \\
\text { meat. }\end{array}$ & $2.71 \pm 0.86$ & $3.14 \pm 0.87$ & $3.08 \pm 0.91$ & \\
\hline Total score & $22 \pm 5.15$ & $23.6 \pm 4.34$ & $25.0 \pm 4.51$ & * \\
\hline
\end{tabular}

A exhibited the lowest scores on all 8 items. There were significant differences $(\mathrm{p}<$ 0.05 ) in scores on the following 4 items among the three groups: Item 1 (I live a regular life), Item 3 (I adjust my work/housework to avoid putting a heavy burden on my body), Item 7 (I take a bath with lukewarm water between $38^{\circ} \mathrm{C}$ and $40^{\circ} \mathrm{C}$ ), and Item 8 (I warm up the bathroom and dressing room before taking a shower on a cold day). The total score on the self-management of stress was significantly higher in Group C participants as compared to those in the other two groups $(\mathrm{p}<0.01)$ (Table 4$)$.

d) Medications

Among the three groups, the score on self-management pertaining to Item 2 (I make sure to take medications even when my blood pressure is stable) was significantly higher in Group B participants $(\mathrm{p}<0.05)$. The score on the 6 other items (except Item 2) was higher in Group C participants. There was a significant difference among the three groups' score on Item 4 (I don't miss taking any medication) $(\mathrm{p}<0.05)$. Among the three groups, the total score on the self-management of medications was the highest among those in Group C (Table 5). 
Table 3. Self management score in exercise management.

\begin{tabular}{|c|c|c|c|}
\hline Item Description & $\begin{array}{l}\text { aged } 65 \text { years or } \\
\text { below (Group } A) \\
\quad(\mathrm{N}=45)\end{array}$ & $\begin{array}{l}\text { early-stage elderly } \\
\quad \text { individuals } \\
\text { (Group B) }(\mathrm{N}=52)\end{array}$ & $\begin{array}{c}\text { late-stage elderly } \\
\text { individuals aged } 75 \\
\text { years or over } \\
\text { (Group C) }(\mathrm{N}=53)\end{array}$ \\
\hline $\begin{array}{l}\text { 1) I engage in moderate whole } \\
\text { body exercise such as swinging } \\
\text { arms and moving legs widely } \\
\text { while taking a walk, walking } \\
\text { quickly, exercise in the pool, } \\
\text { swimming, cycling, } \\
\text { calisthenics to the radio, } \\
\text { and rhythmic exercise. }\end{array}$ & $2.69 \pm 0.94$ & $2.69 \pm 1.17$ & $2.67 \pm 1.23$ \\
\hline $\begin{array}{l}\text { 2) I measure my pulse during } \\
\text { exercise and see if the exercise } \\
\text { is putting a heavy burden } \\
\text { on the body. }\end{array}$ & $1.67 \pm 0.97$ & $1.79 \pm 1.03$ & $1.48 \pm 0.85$ \\
\hline 3) I feel refreshed after exercise. & $2.80 \pm 0.89$ & $2.90 \pm 1.05$ & $2.85 \pm 1.17$ \\
\hline $\begin{array}{l}\text { 4) I exercise indoors when the } \\
\text { weather is bad. }\end{array}$ & $1.66 \pm 0.83$ & $1.92 \pm 1.04$ & $2.04 \pm 1.23$ \\
\hline $\begin{array}{l}\text { 5) I try not to rely too much } \\
\text { on vehicles like cars and } \\
\text { walk instead. }\end{array}$ & $2.42 \pm 0.98$ & $2.85 \pm 1.09$ & $2.58 \pm 1.20$ \\
\hline $\begin{array}{l}\text { 6) I drink water during and } \\
\text { after exercise. }\end{array}$ & $3.40 \pm 0.75$ & $3.50 \pm 0.85$ & $3.52 \pm 0.87$ \\
\hline 7) I try to exercise regularly. & $2.31 \pm 0.94$ & $2.60 \pm 1.01$ & $2.87 \pm 1.14$ \\
\hline $\begin{array}{l}\text { 8) I try to get information } \\
\text { about exercise treatment. }\end{array}$ & $2.09 \pm 0.99$ & $2.46 \pm 1.09$ & $2.60 \pm 1.21$ \\
\hline Total score & $19.2 \pm 4.55$ & $20.7 \pm 5.79$ & $20.7 \pm 6.07$ \\
\hline
\end{tabular}

${ }^{*} \mathrm{p}<0.05,{ }^{* *} \mathrm{p}<0.01$.

\section{e) Drinking alcohol}

As compared to participants in the other two groups, those in Group A exhibited the highest score on Item 2 (I take a break from drinking alcohol a few days in a week). Further, among the three groups, Group C participants exhibited the highest score on the following 3 items (Table 6): Item 1 (when drinking, I decide the amount of alcohol I will consume in advance), Item 3 (when I drink, I drink less than $180 \mathrm{ml}$ Sake or a middle-sized bottle of beer [500 $\mathrm{ml}]$ ), and Item 4 (I try to create an environment and use a device that will help me refrain from drinking excessively).

\section{f) Smoking}

Among the three groups, Group A participants exhibited the highest total score on the self-management of smoking and on three items. The score on Item 2 (I try to create an environment and use a device that will help me refrain from smoking excessively) was the same for participants in Group A and B (Table 7). Further, 26, 37, and 25 individuals in Group A, B, and C, respectively, reported having smoked before. Among those who had smoked before, 9 (34.6\%), 10 
Table 4. Self management score in stress.

\begin{tabular}{|c|c|c|c|c|}
\hline Item Description & $\begin{array}{c}\text { aged } 65 \text { years } \\
\text { or below } \\
\text { (Group A) } \\
(\mathrm{N}=45)\end{array}$ & $\begin{array}{c}\text { early-stage elderly } \\
\text { individuals } \\
\text { (Group B) } \\
(\mathrm{N}=52)\end{array}$ & $\begin{array}{l}\text { late-stage elderly } \\
\text { individuals aged } \\
75 \text { years or over } \\
\text { (Group C) }(\mathrm{N}=53)\end{array}$ & \\
\hline 1) I live a regular life. & $2.87 \pm 0.72$ & $2.87 \pm 0.90$ & $3.54 \pm 0.67$ & $* *$ \\
\hline $\begin{array}{l}\text { 2) I take a rest if I am tired } \\
\text { without overdoing it. }\end{array}$ & $3.16 \pm 0.67$ & $3.31 \pm 0.67$ & $3.57 \pm 0.82$ & \\
\hline $\begin{array}{l}\text { 3) I adjust my work/housework } \\
\text { to avoid putting a heavy burden } \\
\text { on my body. }\end{array}$ & $2.98 \pm 0.65$ & $3.13 \pm 0.88$ & $3.62 \pm 0.59$ & $* *$ \\
\hline $\begin{array}{l}\text { 4) I have someone to talk to or } \\
\text { talk about my troubles, but } \\
\text { when I am stressed, I try not to. }\end{array}$ & $2.91 \pm 0.67$ & $3.15 \pm 0.93$ & $3.35 \pm 0.86$ & \\
\hline $\begin{array}{l}\text { 5) I take sufficient sleep and can } \\
\text { wake up clearly refreshed. }\end{array}$ & $2.96 \pm 0.82$ & $2.92 \pm 0.86$ & $3.29 \pm 0.89$ & \\
\hline $\begin{array}{l}\text { 6) When I go out, and I feel } \\
\text { cold, I have to wear another } \\
\text { coat and remove if when it is } \\
\text { warm. }\end{array}$ & $3.29 \pm 0.62$ & $3.43 \pm 0.72$ & $3.68 \pm 0.64$ & \\
\hline $\begin{array}{l}\text { 7) I take a bath with lukewarm } \\
\text { water between } 38^{\circ} \mathrm{C} \text { and } 40^{\circ} \mathrm{C} \text {. }\end{array}$ & $2.69 \pm 1.04$ & $2.76 \pm 0.98$ & $3.43 \pm 0.91$ & $* *$ \\
\hline $\begin{array}{l}\text { 8) I warm up the bathroom and } \\
\text { dressing room before taking a } \\
\text { shower on a cold day. }\end{array}$ & $2.20 \pm 1.01$ & $2.48 \pm 1.16$ & $3.13 \pm 1.11$ & $* *$ \\
\hline $\begin{array}{l}\text { 9) I obtain information } \\
\text { regarding what to watch } \\
\text { out at the time of bathing. }\end{array}$ & $2.22 \pm 1.04$ & $2.52 \pm 1.07$ & $2.85 \pm 1.13$ & \\
\hline Total score & $25.0 \pm 4.49$ & $26.6 \pm 4.69$ & $30.3 \pm 3.38$ & ** \\
\hline
\end{tabular}

${ }^{*} \mathrm{p}<0.05,{ }^{* *} \mathrm{p}<0.01$.

(27\%), and 1 (4\%) individuals reported smoking currently in Group A, B, and C, respectively. Further, 2 (22\%) participants each in Group A and B, and none of the participants in Group $C$ reported deciding to limit the number of cigarettes smoked per day.

g) Comparison of total scores on each self-management behavior among the three groups

The total scores on self-management behaviors pertaining to diet, exercise, stress, medications, and drinking alcohol were higher among those in Group C as compared to the other two groups. There was a significant difference among the three groups in terms of diet $(p<0.05)$ and stress management $(p<0.05)$. The score on the self-management of smoking was higher in Group A as compared to the other two groups (Table 8).

3) Status of management of blood pressure among the three groups

The mean blood pressures in Group A, B, and C were $137 \pm 17 / 80 \pm 11$ $\mathrm{mmHg}, 136 \pm 16 / 73 \pm 13 \mathrm{mmHg}$, and $143 \pm 19 / 70 \pm 12 \mathrm{mmHg}$, respectively. The average number of antihypertensive medications was two for all three groups, but diastolic blood pressure was significantly lower in Group C as compared to 
Table 5. Self management score in medication management.

\begin{tabular}{|c|c|c|c|c|}
\hline Item Description & $\begin{array}{l}\text { aged } 65 \text { years or } \\
\text { below (Group A) } \\
\qquad(\mathrm{N}=45)\end{array}$ & $\begin{array}{l}\text { early-stage } \\
\text { elderly individuals } \\
\text { (Group B) }(\mathrm{N}=52)\end{array}$ & $\begin{array}{l}\text { late-stage elderly } \\
\text { individuals aged } \\
75 \text { years or over } \\
\text { (Group C) }(\mathrm{N}=53)\end{array}$ & \\
\hline $\begin{array}{l}\text { 1) In accordance with the } \\
\text { doctor's instructions, I } \\
\text { comply with the number of } \\
\text { times, quantity and time of } \\
\text { taking the medicine. }\end{array}$ & $3.77 \pm 0.42$ & $3.85 \pm 0.50$ & $3.91 \pm 0.35$ & \\
\hline $\begin{array}{l}\text { 2) I make sure to take } \\
\text { medications even when my } \\
\text { blood pressure is stable. }\end{array}$ & $3.77 \pm 0.47$ & $3.92 \pm 0.29$ & $3.87 \pm 0.39$ & * \\
\hline $\begin{array}{l}\text { 3) When I take medicine, I } \\
\text { take it with water or I } \\
\text { dissolve the medicine } \\
\text { in my mouth. }\end{array}$ & $3.53 \pm 0.82$ & $3.73 \pm 0.68$ & $3.75 \pm 0.55$ & \\
\hline $\begin{array}{l}\text { 4) I don't miss taking any } \\
\text { medication. }\end{array}$ & $3.66 \pm 0.47$ & $3.77 \pm 0.50$ & $3.87 \pm 0.39$ & * \\
\hline $\begin{array}{l}\text { 5) I exert effort and adjust } \\
\text { my environment so that I do } \\
\text { not forget to take medicine. }\end{array}$ & $3.26 \pm 0.91$ & $3.44 \pm 0.85$ & $3.70 \pm 0.69$ & \\
\hline $\begin{array}{l}\text { 6) When I notice that I have } \\
\text { forgotten to drink medicine, } \\
\text { I will assess based on the } \\
\text { time whether I should drink } \\
\text { medicine or not. }\end{array}$ & $3.18 \pm 0.87$ & $3.04 \pm 1.02$ & $3.38 \pm 0.96$ & \\
\hline $\begin{array}{l}\text { 7) When my body shows } \\
\text { some kind of symptoms, I } \\
\text { can seek a consultation at } \\
\text { the hospital early or can } \\
\text { contact. }\end{array}$ & $3.36 \pm 0.78$ & $3.29 \pm 0.95$ & $3.51 \pm 0.89$ & \\
\hline Total score & $24.5 \pm 3.11$ & $25.0 \pm 2.45$ & $25.9 \pm 2.36$ & \\
\hline
\end{tabular}

${ }^{*} \mathrm{p}<0.05,{ }^{* *} \mathrm{p}<0.01$

Table 6. Self management score in drinking management.

\begin{tabular}{lccc}
\hline \multicolumn{1}{c}{ Item Description } & $\begin{array}{c}\text { aged 65 years } \\
\text { or below } \\
\text { (Group A) } \\
(\mathrm{N}=45)\end{array}$ & $\begin{array}{c}\text { early-stage } \\
\text { elderly individuals } \\
\text { (Group B }) \\
(\mathrm{N}=52)\end{array}$ & $\begin{array}{c}\text { late-stage elderly } \\
\text { individuals aged 75 } \\
\text { years or over } \\
\text { (Group C) }(\mathrm{N}=53)\end{array}$ \\
\hline $\begin{array}{l}\text { 1) When I drink alcoholic beverages, I } \\
\text { decide the amount to drink. }\end{array}$ & $2.69 \pm 1.12$ & $2.88 \pm 1.08$ & $3.27 \pm 1.11$ \\
$\begin{array}{l}\text { 2) I take a break from drinking alcohol a } \\
\text { few days in a week. }\end{array}$ & $3.25 \pm 1.07$ & $2.73 \pm 1.30$ & $2.88 \pm 1.39$ \\
$\begin{array}{l}\text { 3) When I drink, I drink less than 180 ml } \\
\text { Sake or a middle-sized bottle of beer [500 } \\
\text { ml]. (Woman has about half this) }\end{array}$ & $2.56 \pm 1.34$ & $2.64 \pm 1.27$ & $3.12 \pm 1.17$ \\
$\begin{array}{l}\text { 4) I try to create an environment and use a } \\
\text { device that will help me refrain from }\end{array}$ & $2.74 \pm 1.06$ & $2.84 \pm 1.06$ & $3.08 \pm 1.29$ \\
drinking excessively. & $11.1 \pm 3.74$ & $11.0 \pm 3.70$ & $12.3 \pm 4.28$ \\
\begin{tabular}{l} 
Total score \\
\hline
\end{tabular} & & & \\
\hline
\end{tabular}

${ }^{*} \mathrm{p}<0.05,{ }^{* *} \mathrm{p}<0.01$. 
Table 7. Self management score in smoking management.

\begin{tabular}{|c|c|c|c|}
\hline Item Description & $\begin{array}{l}\text { aged } 65 \text { years } \\
\text { or below } \\
\text { (Group A) } \\
(\mathrm{N}=45)\end{array}$ & $\begin{array}{l}\text { early-stage } \\
\text { elderly individuals } \\
\quad(\text { Group B) } \\
(\mathrm{N}=52)\end{array}$ & $\begin{array}{c}\text { late-stage elderly } \\
\text { individuals aged } 75 \\
\text { years or over } \\
\text { (Group C) }(\mathrm{N}=53)\end{array}$ \\
\hline $\begin{array}{l}\text { 1) I have decided the number of cigarettes } \\
\text { to smoke in a day. }\end{array}$ & $2.67 \pm 1.0$ & $2.60 \pm 1.07$ & $2.63 \pm 1.01$ \\
\hline $\begin{array}{l}\text { 2) I try to create an environment and use } \\
\text { a device that will help me refrain from } \\
\text { smoking excessively. }\end{array}$ & $2.67 \pm 1.11$ & $2.50 \pm 1.08$ & $2.58 \pm 1.07$ \\
\hline $\begin{array}{l}\text { 3) When I want to smoke, I try to repress } \\
\text { this urge by doing other actions as a } \\
\text { substitute such as stretching and light } \\
\text { exercise. }\end{array}$ & $1.89 \pm 1.05$ & $1.89 \pm 1.05$ & $1.80 \pm 1.03$ \\
\hline Total score & $7.23 \pm 3.16$ & $6.99 \pm 3.2$ & $7.01 \pm 3.11$ \\
\hline
\end{tabular}

${ }^{*} \mathrm{p}<0.05,{ }^{* *} \mathrm{p}<0.01$

Table 8. Comparison of total self-management behavior total score in 3 groups.

\begin{tabular}{lccc}
\hline \multicolumn{1}{c}{ Item Description } & $\begin{array}{c}\text { aged 65 years } \\
\text { or below } \\
\text { (Group } \mathrm{A}) \\
(\mathrm{N}=45)\end{array}$ & $\begin{array}{c}\text { early-stage } \\
\text { elderly individuals } \\
\text { (Group B) } \\
(\mathrm{N}=52)\end{array}$ & $\begin{array}{c}\text { late-stage elderly } \\
\text { individuals aged } 75 \\
\text { years or over } \\
\text { (Group C) }(\mathrm{N}=53)\end{array}$ \\
\hline 1) Diet management & $22.0 \pm 5.15$ & $23.6 \pm 4.34$ & $25.0 \pm 4.51$ \\
2) Exercise management & $19.2 \pm 4.55$ & $20.7 \pm 5.79$ & $20.7 \pm 6.07$ \\
3) Stress management & $25.0 \pm 4.49$ & $26.6 \pm 4.69$ & $30.3 \pm 3.38$ \\
4) Medication management & $24.5 \pm 3.11$ & $25.0 \pm 2.45$ & $25.9 \pm 2.36$ \\
5) Drinking management & $11.1 \pm 3.74$ & $11.0 \pm 3.70$ & $12.3 \pm 4.28$ \\
6) Smoking management & $7.23 \pm 3.16$ & $6.99 \pm 3.2$ & $7.01 \pm 3.11$ \\
\hline
\end{tabular}

${ }^{*} \mathrm{p}<0.05,{ }^{* *} \mathrm{p}<0.01$.

the other two groups $(\mathrm{p}<0.01)$ (Table 9).

Further, $40 \%$ of those in Group A achieved their lower targeted blood pressure (120 - 129/80 - $84 \mathrm{mmHg})$. Similarly, $61.5 \%$ of the participants in Group B achieved their lower targeted blood pressure (140/90 mmHg). Among Group C participants, $88.7 \%$ achieved their lower targeted blood pressure (150/90 $\mathrm{mmHg}$ ). The number of prescribed medications among the three groups was not significantly different. All groups were mainly prescribed angiotensin II receptor blockers (ARB), calcium channel blockers, angiotensin-converting enzyme (ACE) inhibitors, beta blockers, or acombination of these medications (Figure 1).

Participants in Group A and B were prescribed 3 to 4 types of antihypertensive medications. The distributions of participants whose blood pressure ranged over $140 / 90 \mathrm{mmHg}$ were $15.6 \%, 15.6 \%$, and $11.3 \%$ in Group A, B, and C, respectively (Figure 2). 
Table 9. Status of blood pressure management in three groups.

\begin{tabular}{cccc}
\hline & \multicolumn{3}{c}{ SBP } \\
\hline DBP & $<130 \mathrm{mmHg}$ & $130-140 \mathrm{mmHg}$ & $>140 \mathrm{mmHg}$ \\
\hline \multirow{3}{*}{$>90 \mathrm{mmHg}$} & Group A 0\% & Group A 0\% & Group A 15.6\% \\
& Group B 1.9\% & Group B 1.9\% & Group B 15.6\% \\
& Group C 0\% & Group C 0\% & Group C 11.3\% \\
& Group A 4.4\% & Group A 2.2\% & Group A 6.7\% \\
$90-85 \mathrm{mmHg}$ & Group B 1.9\% & Group B 0\% & Group B 0\% \\
& Group C 0\% & Group C 0\% & Group C 5.7\% \\
& Group A 4.4\% & Group A 4.4\% & Group A 6.7\% \\
& Group B 0\% & Group B 0\% & Group B 3.8\% \\
& Group C 0\% & Group C 0\% & Group C 1.9\% \\
& Group A 35.6\% & Group A 8.9\% & Group A 11.1\% \\
& Group B 50\% & Group B 9.6\% & Group B 21.2\% \\
& Group C 35.8\% & Group C 15.1\% & Group C 30.2\% \\
\hline
\end{tabular}

Group A: aged 65 years or below $(\mathrm{N}=45)$. Group B: early-stage elderly individuals $(\mathrm{N}=52)$. Group C: late-stage elderly individuals aged 75 years or over $(\mathrm{N}=53)$.

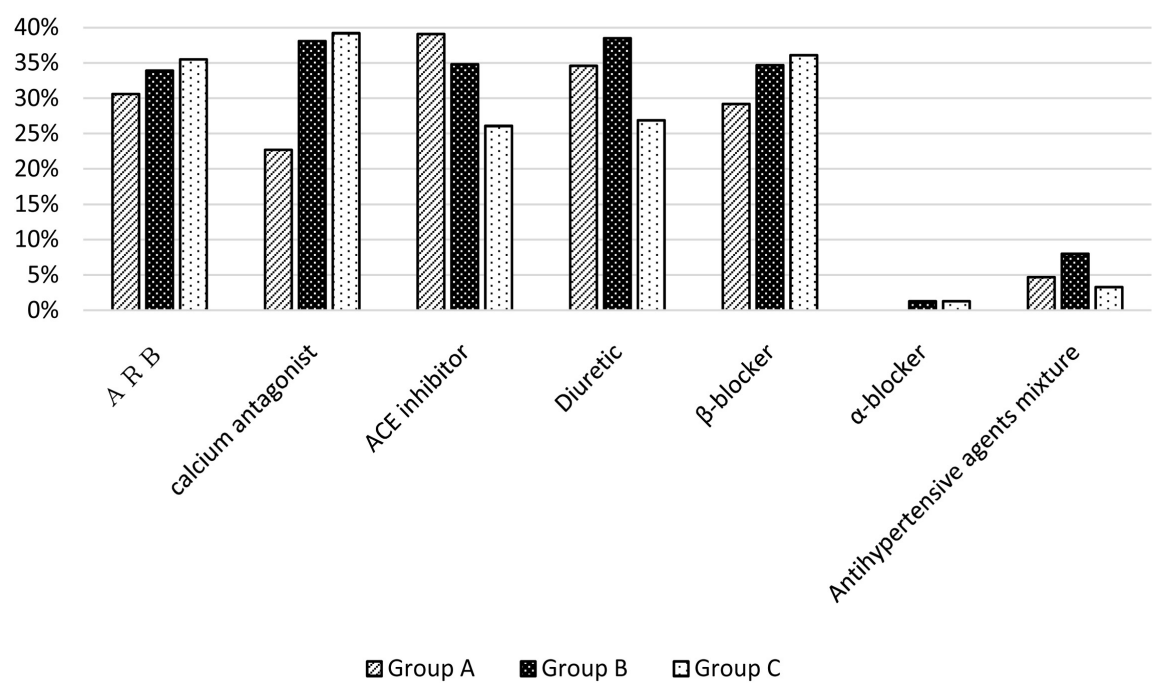

Figure 1. Oral hypertensive agents and proportions taken by each group. Group A: aged 65 years or below. Group B: early-stage elderly individuals. Group C: late-stage elderly individuals aged 75 years or over.

\section{Discussion}

1) Basic attributes of participants

The mean levels observed in the blood tests, including the levels of triglycerides, total cholesterol, low-density the lipoprotein (LDL) cholesterol, and high-density lipoprotein (HDL) cholesterol, appeared within the normal ranges among the three groups. The ABI test for both the left and right sides was in the normal range among those in Groups A and C. In contrast, among those in Group $B$, the left $A B I$ was in the normal range whereas the right $A B I$ was $1.1 \pm$ 0.8 , indicating the potential presence of arterial calcification. These ABI results suggest that the blood vessels are deteriorated and stenosis could develop; 


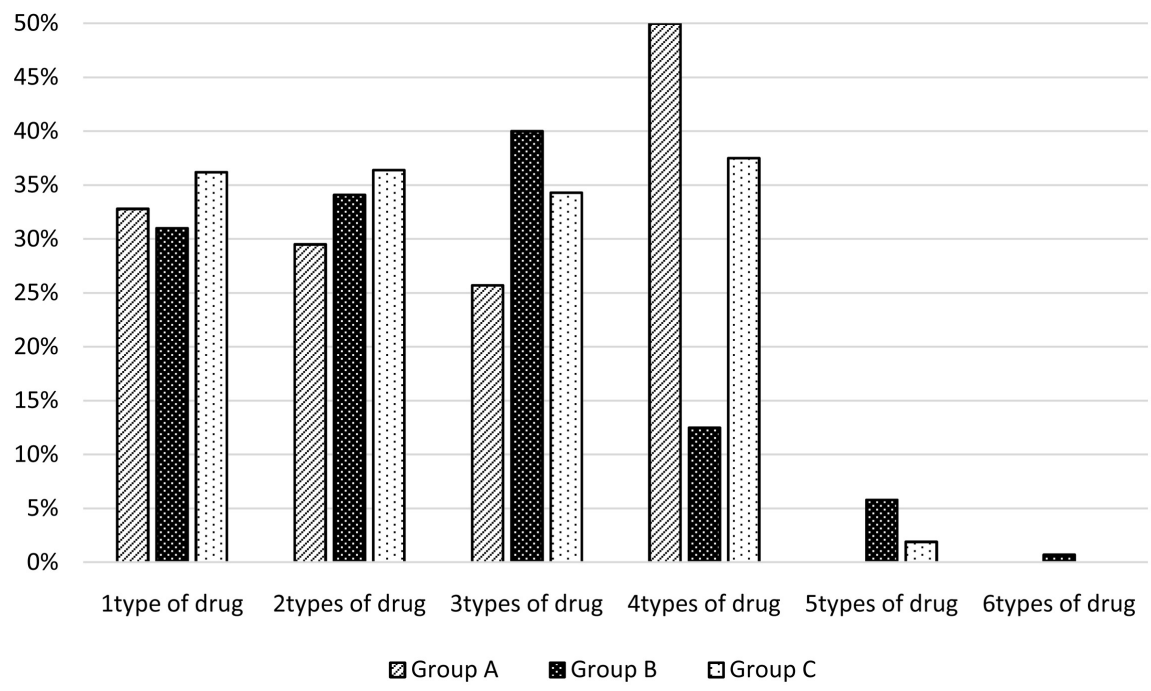

Figure 2. Proportions of antihypertensive drugs administered. Group A: aged 65 years or below. Group B: early-stage elderly individuals. Group C: late-stage elderly individuals aged 75 years or over.

however, it could be partially attributed to age-related deterioration. Regarding PWV, all three groups showed values that were much higher than the reference value of $1400 \mathrm{~cm} / \mathrm{s}$. This result suggests the vessels are stiffening and the velocity of the pulsation generated from the blood ejected from the heart and reaching the limbs through the blood vessels is low, indicating that the degree of arteriosclerosis may be high.

The degree of obesity based on BMI was between normal to Obesity Class II in all three groups. Obesity increases visceral fat and elevates fat in the blood, leading to the development of arteriosclerosis. If the degree of obesity progresses, these three groups, who are already being treated for hypertension, may have an increased risk of arteriosclerosis and the possibility of further increase in their systolic and diastolic blood pressure. Based on the results of ABI, PWV, and BMI, the level of hypertension could be exacerbated and may increase the risk of developing cerebrovascular and cardiovascular disorders. Therefore, it is important to reconsider the lifestyle of these individuals and improve their BMI and vascular health.

\section{2) Control of blood pressure}

The percentage of participants exhibiting blood pressure within the average range for their age was $59.9 \%, 61.5 \%$, and $50.9 \%$ in Group A, B, and C, respectively. The present results revealed insufficient management in the control of diastolic blood pressure in Group A participants, and that of systolic blood pressure in Group C participants. This may occur because the flow of blood declines due to the decreasing elasticity of blood vessels with age, and notably, the systolic blood pressure increases when blood is delivered by the contraction of the heart, and in turn, the diastolic blood pressure decreases [2] [10].

Although more than $50 \%$ of the participants in each group had a blood pressure less than 140/90 $\mathrm{mmHg}$, those in Group C had the highest percentage of 
61.5\%. The following factors can be explained for the high achievement rate in lowering blood pressure to the targeted level: physicians prescribe effective antihypertensive medications; participants visit physicians regularly and take medications as prescribed; and due to the long disease duration, patients understand the importance of maintaining blood pressure at targeted levels. However, as the age increases, it is highly possible that the blood pressure may rise due to an age-related reduction in the elasticity of blood vessels or changes in autonomic nervous functions, which can degrade blood vessel contraction and dilation. In addition, the elevation of blood pressure is correlated with the development of complications of cardiovascular disease, and it is reported that the cardiovascular-related mortality rate increases as the blood pressure increases [11]. A meta-analysis that examined prospective cohort studies reported that the risk of developing complications of brain/cardiovascular diseases increases even when blood pressure is controlled at 120 - 139/80 - $89 \mathrm{mmHg}$ [12]. The 2013 guidelines on hypertension provided by the European Society of Hypertension (ESH) and the European Society of Cardiology (ESC) indicated the association between elevated blood pressure (systolic blood pressure ranging from 110 to $115 \mathrm{mmHg}$ and diastolic blood pressure ranging from 70 to $75 \mathrm{mmHg}$ ) and the increased risk of cerebrovascular/cardiovascular diseases [13]. Based on previous studies, it is critical for these three groups, especially for early- and late-stage elderly individuals, to ensure self-management in controlling blood pressure even though at least half of the participants in each group were successful in lowering their blood pressure to the targeted level.

In the present study, the percentage of medical history of ischemic heart disease and cerebrovascular disease increased with age. This maybe expected because patients with hypertension are more likely to develop complications of the brain/cardiovascular system with aging. Previous studies reported that the elevation of systolic and diastolic blood pressure is associated with the increased risk of mortality relating to cardiovascular or cerebrovascular disorders, indicating the importanceof thoroughly performing antihypertensive management [14] [15] [16] [17]. Furthermore, in order to prevent cerebrovascular and coronary artery disease, it is necessary for patients with hypertension to modify their lifestyle while remaining aware of the risk of brain/cardiovascular complications, including other risk factors, and to engage in self-management behaviors.

3) Self-management behaviors

a) Diet management

In the present study, participants in Group $\mathrm{C}$ exhibited high scores on self-management pertaining to 5 out of the 8 diet-related items. Participants in Group B showed high scores on two items. Specifically, participants' scores were high on items such as refraining from sodium, sweets, and greasy foods, and consuming meals largely made up of vegetables and fish. As older people become less sensitive to salty or sweet tastes due to a decrease in taste cells, they tend to prefer strong flavors. However, since the disease duration was longer in these groups, specifically, $10.5 \pm 3.9$ years and $8.4 \pm 5.1$ years in Group C and B, 
respectively, they may understand the need for diets with reduced sodium and lightly seasoned foods, and may better perform self-management with experience. Good self-management behaviors in diet contribute to maintaining a BMI less than $25 \mathrm{~kg} / \mathrm{m}^{2}$, which is considered normal value among early- and late-stage elderly individuals.

The overall self-management score for diet management was the lowest among those in Group A. This finding suggests that they may have difficulty in realizing the necessity of diet management and were unable to adjust their self-management since the average disease duration was shorter ( $5.8 \pm 4.8$ years) as compared to the other two groups, and some of the participants had hypertension only since one year. Their average BMI of over $25 \mathrm{~kg} / \mathrm{m}^{2}$, which is considered to indicate obesity, could also indicate that individuals in Group A did not engage in proper diet management. In addition, because participants in Group A were aged 46 to 64 years, they may be busy working and may tend to eat out a lot. Consequently, they may not be able to eat regular and well-balanced meals. Therefore, it is important for individuals aged 65 years or below to focus on their weight and BMI, and manage their diet by making changes such as reducing sodium and lightly flavoring foods, to prevent a further increase in their blood pressure and to improve their blood pressure control.

It is critical that patients with hypertension improve their lifestyle by modifying eating habits and managing their diet appropriately. The Dietary Approaches to Stop Hypertension (DASH) has a hypotensive effect, and it is reported to have a remarkable hypotensive effect especially when combined with salt restriction [18] [19]. The DASH is based on a complex diet focusing on the intake of vegetables, beans, fish, and grains, and limiting high fat/high cholesterol foods such as meat and sweets, designed specifically as a therapy for hypertension. It is necessary to implement nursing practices that collaborate with nutritionists so that patients reconsider their eating habits and improve their dietary habits by incorporating DASH meals corresponding to individual lifestyles and food preferences. Especially, the provision of focused guidance on improving eating habits is important for patients aged 65 years and younger since the diet self-management score was low in this group.

b) Exercise management

Among the 8 items in exercise management, individuals in Group B and C had higher scores on 3 and 5 items, respectively. Among the three groups, the self-management score was the highest in Group C, while Group A participants exhibited the lowest self-management scores on all items. Because Group C participants had a longer disease duration, they were more likely to understand the importance of engaging in moderate exercise for hypertension. Further, Group B and $\mathrm{C}$ individuals may have had higher self-management scores on exercise because they had already retired from work and had enough time to exercise daily. Additionally, their higher scores may be explained by their ability to engage in aerobic exercises, such as walking or calisthenics to the radio, at their own pace, 
without the physical burden of decrease in muscle, muscle mass, or physical strength with age.

It can be assumed that individuals aged 65 years and younger may be busy working, and therefore, they may have difficulty in making time for exercising regularly. Exercise increases the flexibility of blood vessels, which can contribute to lowering blood pressure. Moderate aerobic exercise carries oxygen and nutrition to the muscles, expands blood vessels, and decreases activity of the sympathetic nervous system, thus lowering blood pressure. Lack of exercise may lead to poor blood circulation and obesity, and it may increase blood pressure. As weight loss and exercise have a hypotensive effect, the JSH recommends weight reduction to the appropriate level (BMI less than $25 \mathrm{~kg} / \mathrm{m}^{2}$ ) and periodically engaging in aerobic exercise for more than 30 minutes [2]. Therefore, it is necessary for people aged 65 years and younger to make a habit of engaging in aerobic exercises, such as walking to the destination or using the stairs. These findings reveal the urgent need to provide guidance with easy to follow instructions for patients to engage in aerobic exercise.

c) Stress management

Self-management scores on all stress-related items were the highest in Group $\mathrm{C}$ participants and the lowest in Group A participants. The duration of hypertension and medical treatment among Group $\mathrm{C}$ participants was about twice that of those in Group A. Thus, the former may better understand what kind of behaviors burden the body and affects blood pressure, which could explain their better stress management scores. Further, most Group C participants were retired, such that they had more time to focus on their own physical condition. Their higher scores may also be explained by the fact that they understood that their physical function and reserve capacity declined with age, and that their physical condition would deteriorate further with poor blood pressure control. This awareness of the increased risk of triggering complications and deterioration of health may motivate them to engage in better self-management.

d) Medication management

In general, late-stage elderly individuals may have a reduced ability to manage medications because they are less likely to understand the significance of medications, may have insufficient understanding of dosage and effects of medications due to hearing loss and visual acuity, and may lose drug sheets and medicine packages [2]. However, in this study, the medication self-management score of the late elderly population was the highest among the three groups. This is medication adherence is considered good because of the amount of medications is not large. Also, it would be good for patients to understand the meaning and necessity of taking medication as instructed by a doctor because of the long duration of the disease. Furthermore, it is also predicted that the doctor prescribes medication by planning the type of medicine so that the number of medications are minimized in consideration of the age-related degree of understanding of the patient. A significant difference between the three groups' scores was observed 
for two items, "take medications even when blood pressure is stable" and "make sure to take medications." The number of medications prescribed was within 1 to 3 medications among the three groups, and it was assumed that they understood that their blood pressure increases without medications, leading to an increased risk in the onset of serious diseases and complications. Therefore, they may engage in better medication self-management to maintain their lower targeted blood pressure. As such, the medication adherence was high in all three groups in this study. A previous study indicated that the number of medications, number of administrations, and timing of taking medications were the most important factors affecting adherence, and that adherence decreases as the number of administrations increases [20]. Another study reported that a lower number of medications increases medication adherence [21]. The results of the present study are consistent with those of previous studies because majority of the present participants took 1 to 3 medications, and their medication self-management was optimal owing to the lower number of prescribed medications. Maintaining adequate adherence is the most important self-management behavior.

e) Drinking alcohol

The self-management score pertaining to taking a break from drinking alcohol for a few days out of a week was high in Group A participants. In general, individuals aged 65 years and younger tend to be in upper managerial positions, and they have important responsibilities at work, have many opportunities to drink at business dinners, and reduce stress from the heavy pressure of work by drinking. Evidently, as this age group has several opportunities to drink alcohol, they may engage in self-management by making an effort not to drink on certain days of the week.

Group C participants had the highest scores on 3 out of the 4 items on self-management pertaining to drinking alcohol. Drinking alcohol has multiple adverse effects, including those on the gastrointestinal system (liver and stomach), cardiovascular system, cerebrovascular system, and central nervous system. In addition, physical function as well as alcohol decomposition function decreases with age. Thus, participants in Group C may have been aware of the harmful health effects of drinking alcohol, which may have motivated them to make it habit to drink appropriate amounts.

Alcohol consumption is associated with blood pressure. Numerous domestic and international studies on the impact of drinking alcohol on blood pressure have suggested that the increase in alcohol consumption and blood pressure is proportional. That is, the association is amount-dependent; blood pressure increases as alcohol consumption increases [22] [23]. From of this viewpoint, it is important for patients with hypertension to consciously practice drinking moderate amounts and to make sure that their drinking habits do not adversely affect their physical condition.

f) Smoking management 
The 10 cohort studies that were conducted as a part of the EPOCH-JAPAN revealed that smokers with hypertension had the highest mortality hazard related to cardiovascular disease [24]. Smoking is the major risk factor that progresses to arteriosclerosis and leads to complications of cardiovascular diseases, leading to a further deterioration in the patient's cardiovascular condition until death [24].

In the present study, participants in Group A had the highest self-management score on the three items and the total score related to smoking management. The self-management score on Item 2, "I try to create an environment and use a device that will help me refrain from smoking excessively," was the same for Group A and B participants. This may be explained by the recognition that the impact of tobacco on health is becoming a common awareness in the society, smoking cessation is highly recommended, and in recent years, the ban on smoking at public facilities and on public transportation has been implemented more strictly. In particular, there are many opportunities to feel the social situation of quitting smoking daily when under the age of 65 years, which plays a big social role. Therefore, their awareness about the importance of smoking cessation is high, which may have led to high scores on smoking self-management in Group A participants in the present study.

On the other hand, looking at the smoking habits of the three groups, although there is consciousness of smoking from the ratio of smokers who currently smoked and smokers who decided the number of cigarettes smoked, it is conceivable that there is no behavior of smoking cessation. Therefore, there is a need to provide guidance on smoking cessation for individuals belonging to all three age groups. Specifically, while Group A participants had higher awareness of smoking cessation, they reported taking fewer actions to quit smoking. Accordingly, the health guidance provided by nurses should focus on the necessity of smoking cessation and should include knowledge on diseases related to smoking and the risk factors.

\section{Prospects for Establishing a Nursing Support Program}

Without appropriate self-management, hypertension may accelerate arteriosclerosis and increase the risk of complications such as cerebrovascular disease, cardiovascular disease, coronary artery disease, and renal disease. Therefore, it is important for patients with hypertension to reconsider their lifestyle, perform appropriate self-management, and control blood pressure at the target value. Nurses are required to provide nursing interventions to support such patients to continuously engage in appropriate self-management behaviors.

While cooperating with physicians and sharing information on patients' conditions, nurses need to provide patients with appropriate education to deepen their understanding of the disease and specific self-management behaviors. This, in turn, would facilitate their performance of effective self-management. Therefore, there is an urgent need to establish a hypertension education program at outpatient clinics and to strengthen patient education. Further, considering the 
recommendation of Hypertension Treatment Guideline 2014, the contents of such hypertension education programs should include the following: 1) information about hypertension-related diseases and complications; 2) modification of lifestyle; 3) self-management related to diet, exercise, stress, medication, drinking alcohol, and smoking; 4) methods of measuring blood pressure at home and maintaining a record in a notebook; and 5) consultation with nurses. Implementing such hypertension education programs could facilitate meticulous nursing practice according to the differences in individual patients' habits, lifestyle, and self-management behaviors. This nursing support may improve the awareness of patients' self-management, leading to more successful self-management, which will in turn contribute to a reduction in medical expenses.

\section{Limitations of Study}

In this study, data was collected at one facility, and there were many subjects aged 65 years and older.

Therefore, the present data may only reflect the self-management of a proportion of patients with hypertension. In the future, it will be necessary to increase the number of facilities to collect data and the number of subjects, and to repeat the study while taking into consideration the age group of the subjects.

\section{Conclusion}

This study investigated self-management behaviors pertaining to diet, exercise, stress, medication, drinking alcohol, and smoking in the daily life of patients with hypertension. These self-management behaviors were examined by classifying the participants into three groups of individuals aged under 65 years (Group A), early-stage elderly individuals (Group B), and late-stage elderly individuals (Group C). Group C participants had higher self-management scores for diet, exercise, stress, medication, and drinking alcohol. Group A participants showed high self-management scores on awareness regarding smoking cessation, but there was a gap between their awareness and actual smoking self-management behavior. Overall, the present results indicate the urgent need to provide individuals aged 65 years and younger with nursing support to reconsider their lifestyle, especially that pertaining to diet, exercise, stress, medications, alcohol consumption and smoking. This would in turn improve their self-management ability and enable them to engage in appropriate self-management behaviors. Pertaining to the background of the present participants, PMW showed high degree of arteriosclerosis, indicating the higher future risk of developing disorders relating to brain/cardiovascular system. Therefore, it is critical that patients with hypertension engage in appropriate self-management behaviors for the prevention of the onset of complications.

\section{Acknowledgements}

Great appreciation is due to the study participants, the study site, and the spe- 
cially appointed Professor Akira Yamashina of Tokyo Medical University. Sincere thanks to Associate Professor Keiko Tsubot of Toyama University for allowing the use his study instrument/scale. The support of specially appointed Professor Syuhei Ryu of Himeji University is also much appreciated. This study was supported by a Japan Society for the Promotion of Science Grant-in-Aid for Scientific Research (Research Startup, Number 25893248).

\section{Conflicts of Interest}

The authors declare no conflicts of interest regarding the publication of this paper.

\section{References}

[1] (2012) Journal of Health and Welfare Statistics. General Foundation Japan Health, Labor Statistics Association, Tokyo, Japanese.

[2] (2014) The Japan Society of Hypertension Association Hypertension Treatment Guidelines Creation Committee. Japan Society of Hypertension Treatment Guidelines, Japan Hypertension Society, Tokyo, Japanese.

[3] (2014) Heisei 26 Year Overview of Patient Survey. Ministry of Internal Affairs and Communications, Ministry of Health Labour and Welfare, Japanese. https://www.mhlw.go.jp/toukei/saikin/hw/kanja/14/

[4] Ueshima, H. (2007) Explanation for the Japanese Paradox: Prevention of Increase in coronary Heart Disease and Reduction in Stroke. Journal of Atherosclerosis and Thrombosis, 14, 278-286.

[5] Arima, H., Tanizaki, Y., Kiyohara, Y., Tsuchihashi, T., Kato, I., Kubo, M., et al. (2003) Validity of the JNC VI Recommendations for the Management of Hypertension in a General Population of Japanese Elderly: The Hisayama Study. Archives of Internal Medicine, 163, 361-366. https://doi.org/10.1001/archinte.163.3.361

[6] Lawes, C.M., Rodgers, A. and Bennett, D.A. (2003) Blood Pressure and Cardiovascular Disease in the Asia Pacific Region. Journal of Hypertension, 21, 707-716. https://doi.org/10.1097/00004872-200304000-00013

[7] (2000) Health Japan 21 Cardiovascular Disease. Ministry of Health, Labour and Welfare, Japanese. https://www.mhlw.go.jp/www1/topics/kenko21_11/b8f.html

[8] Midgley, J.P., Matthew, A.G., Greenwood, C.M. and Logan, A.G. (1996) Effect of Reduced Dietary Sodium on Blood Pressure, a Meta-Analysis of Randomized Controlled Trials. The Journal of the American Medical Association, 275, 1590-1597.

[9] (2009) The Japan Society of Hypertension Association Hypertension Treatment Guidelines Creation Committee. Japan Society of Hypertension Treatment Guidelines, Japan Hypertension Society, Tokyo, Japanese.

[10] (1998) Intersalt: An International Study of Electrolyte Excretion and Blood Pressure. Results for 24 Hour Urinary Sodium and Potassium Excretion. Intersalt Cooperative Research Group. British Medical Journal, 297, 319-328. https://doi.org/10.1136/bmj.297.6644.319

[11] (1994) National High Blood Pressure Education Program Working Group Report on Hypertension in the Elderly. National High Blood Pressure Education Program Working Group. Hypertension, 23, 275-285. https://doi.org/10.1161/01.HYP.23.3.275

[12] Asayama, K., Ohkubo, T., Yoshida, S., Suzuki, K., Metoki, H., Harada, A., et al., Ja- 
pan Arteriosclerosis Longitudinal Study (JALS) Group (2009) Stroke Risk and Antihypertensive Drug Treatment in the General Population: The Japan Arteriosclerosis Longitudinal Study. Journal of Hypertension, 27, 357-364. https://doi.org/10.1097/HJH.0b013e32831967ca

[13] Mancia, G., Fagard, R., Narkiewicz, K., Redón, J., Zanchetti, A., Böhm, M., et al. (2013) 2013 ESH/ESC Guidelines for the Management of Arterial Hypertension: The Task Force for the Management of Arterial Hypertension of the European Society of Hypertension (ESH) and of the European Society of Cardiology (ESC). Journal of Hypertension, 31, 1281-1357. https://doi.org/10.1097/01.hjh.0000431740.32696.cc

[14] Vokonas, P.S., Kannel, W.B. and Cupples, L.A. (1998) Epidemiology and Risk of Hypertension in the Elderly: The Framingham Study. Journal of Hypertens Supplement, 6, 3-9.

[15] Kannel, W.B. (1999) Histolic Perspectives on the Relative Contributions of Diastolic and Systolic Blood Pressure Elevation to Cardiovascular Risk Profile. American Heart Journal, 138, S205-S210. https://doi.org/10.1016/S0002-8703(99)70311-X

[16] Franklin, S.S., Kahn, S.A., Wong, N.D., Larson, M.G. and Levy, D. (1999) Is Pulse Pressure Useful in Predicting Risk for Coronary Heart Disease. The Framingham Heart Study. Circulation, 100, 354-360. https://doi.org/10.1161/01.CIR.100.4.354

[17] Kannel, W.B. (2000) Elevated Systolic Blood Pressure as a Cardiovascular Risk Factor. The American Journal of Cardiology, 85, 251-255. https://doi.org/10.1056/NEJM199704173361601

[18] Appel, L.J., Moore, T.J., Obarzanek, E., Vollmer, W.M., Svetkey, L.P., Sacks, F.M., et al., DASH Collaborative Research Group (1997) A Clinical Trial of the Effects of Dietary Patterns on Blood Pressure. The New England Journal of Medicine, 336, 1117-1124. https://doi.org/10.1056/NEJM199704173361601

[19] Sacks, F.M., Svetkey, L.P., Vollmer, W.M., Appel, L.J., Bray, G.A., Harsha, D., et al., DASH-Sodium Collaborative Research Group (2001) Effects on Blood Pressure of Reduced Dietary Sodium and the Dietary Approaches to Stop Hypertension (DASH) Diet. The New England Journal of Medicine, 344, 3-10. https://doi.org/10.1056/NEJM200101043440101

[20] Coleman, C.I., Roberts, M.S., Sobieraj, D.M., Lee, S., Alam, T. and Kaur, R. (2012) Effect of Dosing Frequency on Chronic Cardiovascular Disease Medication Adherence. Current Medical Research and Opinion, 28, 669-680. https://doi.org/10.1185/03007995.2012.677419

[21] Kim, S., Shin, D.W., Yun, J.M., Hwang, Y., Park, S.K., Ko, Y.-J. and Cho, B. (2016) Medication Adherence and the Risk of Cardiovascular Mortality and Hospitalization Among Patients With Newly Prescribed Antihypertensive Medications. Hypertension, 67, 506-512. https://doi.org/10.1161/HYPERTENSIONAHA.115.06731

[22] Ueshima, H., Mikawa, K., Baba, S., Ozawa, H., Tsushima, M., Kawaguchi, A., Omae, T., Katayama, Y. and Kayamori, Y. (1993) Effect of Reduced Alcohol Consumption on Blood Pressure in Untreated Hypertensive Me. Hypertension, 21, 248-252. https://doi.org/10.1161/01.HYP.21.2.248

[23] Xin, X., He, J., Frontini, M.G., Ogden, L.G., Motsamai, O.I. and Whelton, P.K. (2001) Effects of Alcohol Reduction on Blood Pressure: A Meta-Analysis of Randomized Controlled Trials. Hypertension, 38, 1112-1117. https://doi.org/10.1161/hy1101.093424

[24] Nakamura, K., Nakagawa, H., Sakurai, M., Murakami, Y., Irie, F., Fujiyoshi, A., et 
al., EPOCH-JAPAN Research Group (2012) Influence of Smoking Combined with Another Risk Factor on the Risk of Mortality from Coronary Heart Disease and Stroke: Pooled Analysis of 10 Japanese Cohort Studies. Cerebrovascular Diseases, 33, 480-491. https://doi.org/10.1159/000336764 


\section{Appendix}

\section{"Measure the Self-Care of Patient with Hypertension" Questionnaire}

Please tell us about your daily life. Please complete the following questionnaire. Name: Gender: $\square \mathrm{M} \quad \square \mathrm{F}$

Birth:

[Diet]

\begin{tabular}{ccccc}
\hline No & $\begin{array}{c}\text { Somewhat } \\
\text { no }\end{array}$ & $\begin{array}{c}\text { Somewhat } \\
\text { yes }\end{array}$ & Yes \\
\hline
\end{tabular}

1) I refrain from foods high in sodium such as pickles, tsukudani [fish or seaweed boiled with soy], ham, himono [dried fish], and salted fish.

2) I eat mainly vegetables and fish eat mainly vegetables and fish.

3) I try to eat lightly flavored foods.

4) I try not to gain weight.

5) I refrain from meat and greasy foods.

6) I refrain from sweet snacks and juices.

7) I eat foods with reduced sodium.

8) I avoid foods that contain cholesterol, such as eggs, fish eggs, fish eaten with internal organs, liver, and fatty part of meat.

[Exercise]

\begin{tabular}{ccccc}
\hline No & $\begin{array}{c}\text { Somewhat } \\
\text { no }\end{array}$ & $\begin{array}{c}\text { Somewhat } \\
\text { yes }\end{array}$ & Yes \\
\hline
\end{tabular}

1) I engage in moderate whole body exercise such as swinging arms and moving legs widely while taking a walk, walking quickly, exercise in the pool, swimming, swimming, cycling, calisthenics to the radio, and rhythmic exercise.

2) I measure my pulse during exercise and see if the exercise is putting a heavy burden on the body.

3) I feel refreshed after exercise.

4) I exercise indoors when the weather is bad.

5) I try not to rely too much on vehicles like cars and walk instead.

6) I drink water during and after exercise.

7) I try to exercise regularly.

8) I try to get information about exercise treatment. 
[Stress]

1) I live a regular life.
2) I take a rest if I am tired without
overdoing it.
3) I adjust my work/housework to avoid
putting a heavy burden on my body.
4) I have someone to talk to or talk about my
troubles, but when I am stressed, I try not to.
5) I take sufficient sleep and can wake up
clearly refreshed.
6) When I go out, and I feel cold, I have to
wear another coat
and remove if when it is warm.
7) I take a bath with lukewarm water between
38 $8^{\circ} \mathrm{C}$ and $40^{\circ} \mathrm{C}$.
8) I warm up the bathroom and dressing room
before taking a shower on a cold day.
9) I obtain information regarding what to
watch out at the time of bathing.
no

[Medications]

\begin{tabular}{ccccc}
\hline & No & Somewhat & Somewhat & Yes \\
\end{tabular}

1) In accordance with the doctor's instructions, I comply with the number of times, quantity and time of taking the medicine.

2) I make sure to take medications even when my blood pressure is stable.

3) When I take medicine, I take it with water or I dissolve the medicine in my mouth.

4) I don't miss taking any medication.

5) I exert effort and adjust my environment so that I do not forget to take medicine.

6) When I notice that I have forgotten to drink medicine, I will assess based on the time whether I should drink medicine or not.

7) When my body shows some kind of symptoms, I can seek a consultation at the hospital early or can contact . 
[Drinking]

\begin{tabular}{lcccc}
\hline No & $\begin{array}{c}\text { Somewhat } \\
\text { no }\end{array}$ & $\begin{array}{c}\text { Somewhat } \\
\text { yes }\end{array}$ & Yes
\end{tabular}

1) When I drink alcoholic beverages, I decide the amount to drink.

2) I take a break from drinking alcohol a few days in a week.

3) When I drink, I drink less than $180 \mathrm{ml}$ Sake or a middle-sized bottle of beer [500 $\mathrm{ml}$. (Woman has about half this)

4) I try to create an environment and use a device that will help me refrain from drinking excessively.

[Smoking]

\begin{tabular}{ccccc}
\hline No & $\begin{array}{c}\text { Somewhat } \\
\text { no }\end{array}$ & $\begin{array}{c}\text { Somewhat } \\
\text { yes }\end{array}$ & Yes \\
\hline
\end{tabular}

1) I have decided the number of cigarettes to smoke in a day.

2) I try to create an environment and use a device that will help me refrain from smoking excessively.

3) When I want to smoke, I try to repress this urge by doing other actions as a substitute such as stretching and light exercise.

Thank you for cooperation survey. 